\title{
MicroRNA-29-3p regulates the $\beta$-catenin pathway by targeting IGF1 to inhibit the proliferation of prolactinoma cells
}

\author{
JIE XIA ${ }^{1}$, SONGMEI LI ${ }^{1}$, DIANFEI MA ${ }^{1}$, WENYUJIE GUO ${ }^{2}$, HONG LONG $^{3}$ and WEIPING YIN ${ }^{3}$ \\ ${ }^{1}$ Department of Pharmacy, Yunnan Hospital of Traditional Chinese Medicine, Kunming, Yunnan 650021; \\ ${ }^{2}$ Department of Pediatrics, Kunming Hospital of Traditional Chinese Medicine, Kunming, Yunnan 650011; \\ ${ }^{3}$ Department of Pediatrics, Yunnan University of Traditional Chinese Medicine, \\ Kunming, Yunnan 650500, P.R. China
}

Received October 21, 2020; Accepted March 16, 2021

DOI: $10.3892 / \mathrm{mmr} .2021 .12071$

\begin{abstract}
The present study aimed to analyze the effects and underlying mechanisms of microRNA (miR)-29-3p on the proliferation and secretory abilities of prolactinoma cells by targeting insulin-like growth factor (IGF)- $1 / \beta$-catenin. The relationship between miR-29a-3p and the survival of prolactinoma cells was analyzed with the Kaplan-Meier method in reference to The Cancer Genome Atlas. The expression levels of miR-29a-3p and IGF-1 in MMQ and GH3 cells were detected. A dual-luciferase reporter gene assay was performed to verify the combination of miR-29a-3p and IGF-1. Cells were transfected with a miR-29a-3p mimic and/or IGF-1 pcDNA3.1 to analyze the effects on the proliferation, apoptosis and secretion of prolactin (PRL) and growth hormone $(\mathrm{GH})$ of prolactinoma cells. The effects on $\beta$-catenin in the cytoplasm and nucleus were investigated by western blot analysis. The results showed that miR-29a-3p expression was low in MMQ and GH3 cells. Overexpression miR-29a-3p inhibited IGF-1 mRNA and protein expression. miR-29a-3p inhibited cell proliferation and PRL and GH expression, and promoted apoptosis by inhibiting IGF-1. Increasing the expression of miR-29a-3p increased $\beta$-catenin levels in the cytoplasm, whereas IGF- 1 promoted $\beta$-catenin activation and entry into the nucleus, and reversed the inhibitory effects of miR-29a-3p on $\beta$-catenin. To conclude, miR-29a-3p inhibited the proliferation and secretory abilities of prolactinoma cells by inhibiting nuclear translocation of $\beta$-catenin via a molecular mechanism that is inseparable from IGF-1.
\end{abstract}

Correspondence to: Professor Weiping Yin, Department of Pediatrics, Yunnan University of Traditional Chinese Medicine, 1076 Yuhua Road, Chenggong, Kunming, Yunnan 650500, P.R. China

E-mail: ywpxj2021@163.com; 1147797527@qq.com

Key words: prolactinoma, microRNA-29a-3p, insulin-like growth factor- $1, \beta$-catenin, prolactin, growth hormone

\section{Introduction}

The incidence of pituitary prolactinoma is reportedly 27 cases per million individuals per year $(1,2)$. Abnormal levels of prolactin (PRL) and growth hormone $(\mathrm{GH})$ in patients with prolactinoma can lead to dysregulation of the central gonadal axis $(3,4)$ and central precocious puberty in children $(5)$. Current treatments of pituitary tumors are mainly based on hormone therapy and surgery, with auxiliary chemotherapy and radiotherapy (6). However, the risks of surgical complications and side effects of drugs can limit the benefits of such treatment regimens $(7,8)$.

Insulin-like growth factor (IGF)-1 is a polypeptide that regulates growth and metabolism $(9,10)$, and was previously found to promote tumor development (11). IGF-1 can increase the resistance of gliomas to temozolomide via the Wnt/ $\beta$-catenin pathway (12), promote the proliferation of tumor cells, stimulate the endocrine effect of prolactinoma (13), and accelerate mitosis of prolactinoma cells (14). However, the cancer-promoting mechanism of IGF-1 remains unclear.

MicroRNA (miRNA/miR) is involved in the posttranscriptional regulation of gene expression and can induce the degradation of mRNA by targeting the 3'-untranslated region (UTR) (15). In prolactinoma, miRNAs, such as miR-93-5p (16), miR-145-5p (17) and miR-1299 (18), have regulatory functions. miR-29-3p has tumor suppressor effects in stomach (19), bone (20) and breast (21) cancer. Moreover, miR-29 can affect the growth of rats by inhibiting the expression of IGF-1 (22). However, the role of miR-29-3p in prolactinoma is still unclear.

Therefore, the aim of the present study was to determine the effects of miR-29a-3p on the proliferation and apoptosis of prolactinoma cells, as well as the secretion of PRL and GH via the IGF-1 and $\beta$-catenin pathways.

\section{Materials and methods}

Bioinformatics analysis. The relationship between miR-29a-3p and the survival of patients with prolactinoma (i.e., pheochromocy toma and paraganglioma) was analyzed using the log-rank test via Kaplan-Meier (http://kmplot.com/analysis/index. php? $\mathrm{p}=$ background). In The Cancer Genome Atlas (TCGA) 
database, a total of 179 patients with pheochromocytoma and paraganglioma were included. However, the database does not separate the two tumors. Of the 179 patients, 69 had low expression of miR-29a-3p and 110 had high expression.

Cell culture and transfection. Rat pituitary adenoma RC-4B/C cells [American Type Culture Collection (ATCC); ATCC ${ }^{\circledast}$ CRL-1903] and prolactinoma MMQ (ATCC ${ }^{\circledR}$ CRL-10609) and GH3 (ATCC ${ }^{\circledast}$ CCL-82.1) cells were cultured in F-12K medium (Gibco; Thermo Fisher Scientific, Inc.) supplemented with $2.5 \%$ fetal bovine serum (Gibco; Thermo Fisher Scientific, Inc.) and $15 \%$ horse serum (HyClone; Cytiva) at $37^{\circ} \mathrm{C}$ under a humidified atmosphere of $5 \% \mathrm{CO}_{2} / 95 \%$ air.

MMQ and GH3 cells were divided into 4 groups: $\mathrm{NC}$, mimic, mimic + IGF-1 and IGF-1. According to the group, miR-29a-3p and/or IGF-1 were overexpressed by transfection. Plasmids encoding the full-length human IGF-1 (pcDNA3.1), a miR-29a-3p mimic and corresponding negative control (NC, 3'-GGACAC UAUCUGACAUCGACUA-5') were purchased from Shanghai GenePharma Co., Ltd. Cells $\left(1 \times 10^{5}\right)$ were transfected with 100 pmol pcDNA3.1 or $50 \mathrm{nM}$ mimic $\left(7^{\circ} \mathrm{C}, 5 \% \mathrm{CO}_{2}, 48 \mathrm{~h}\right)$ using Lipofectamine ${ }^{\circledR} 2000$ transfection reagent (Invitrogen; Thermo Fisher Scientific, Inc.). All subsequent experiments were performed within $24 \mathrm{~h}$ after the completion of transfection.

Dual-luciferase reporter assay. Mutated (Mut) IGF-1 was designed based on binding sites that were predicted with the TargetScan v7.2 (http://www.targetscan.org/vert_72/). Cells $\left(1 \times 10^{4}\right)$ were seeded in 96-well plates. After $24 \mathrm{~h}$ of culture, the cells were transfected with wild-type (Wt)/Mut IGF-1 and miR-29a-3p mimic/NC cloned into pMIR-REPORT ${ }^{\text {TM }}$ luciferase vectors (Ambion; Thermo Fisher Scientific, Inc.) using Lipofectamine 2000 transfection reagent. Mut IGF-1 was induced by rapid site-directed mutagenesis kit (Beyotime Institute of Biotechnology). The concentration of Wt/Mut IGF-1 and miR-29a-3p mimic/NC were $1 \mu \mathrm{g}$ and $50 \mathrm{nM}$, respectively. After $48 \mathrm{~h}$, the Dual-Luciferase Reporter 1000 Assay System (Promega Corporation) was used to evaluate Luciferase/Renilla values.

Reverse transcription-quantitative PCR (RT-qPCR). Total RNA was isolated from cells using TRIzol ${ }^{\circledR}$ reagent (Sigma-Aldrich; Merck KGaA). For miR-29a-3p, complementary DNA was synthesized using the miScript kit $\left(60 \mathrm{~min}\right.$ at $42^{\circ} \mathrm{C}, 5 \mathrm{~min}$ at $70^{\circ} \mathrm{C}$, and then stored at $4^{\circ} \mathrm{C}$ ) and amplified with the miScript SYBR Green PCR kit $\left(40\right.$ cycles at $95^{\circ} \mathrm{C}$ for $10 \mathrm{~min}, 94^{\circ} \mathrm{C}$ for $15 \mathrm{sec}, 60^{\circ} \mathrm{C}$ for $1 \mathrm{~min}, 60^{\circ} \mathrm{C}$ for $1 \mathrm{~min}$ and then stored at $4^{\circ} \mathrm{C}$ ) (both from Qiagen $\mathrm{GmbH}$ ), RT kit was used according to the manufacturer's protocol. The quantity of the RT-qPCR products was compared to that of U6 as a standardized reference. IGF-1 mRNA was reverse transcribed $\left(60 \mathrm{~min}\right.$ at $42^{\circ} \mathrm{C}, 5 \mathrm{~min}$ at $70^{\circ} \mathrm{C}$, and then stored at $\left.4^{\circ} \mathrm{C}\right)$ and amplified by RT-qPCR ( 40 cycles at $95^{\circ} \mathrm{C}$ for $10 \mathrm{~min}, 94^{\circ} \mathrm{C}$ for $15 \mathrm{sec}, 60^{\circ} \mathrm{C}$ for $1 \mathrm{~min}, 60^{\circ} \mathrm{C}$ for $1 \mathrm{~min}$, and then stored at $4^{\circ} \mathrm{C}$ ) with the PrimeScript RT kit and SYBR Premix Ex Taq ${ }^{\mathrm{TM}}$ kit (both purchased from Takara Bio, Inc.), respectively. The primers used for RT-qPCR analysis were manufactured by Wuhan GeneCreate Biological Engineering Co., Ltd. Glyceraldehyde 3-phosphate dehydrogenase (GAPDH) was used as an internal reference for mRNA. IGF-1 mRNA levels were quantified using the $2^{-\Delta \Delta C q}$ method (23). The primer sequences were as follows: IGF-1 forward, 5'-TGGTGGACG
CTCTTCAGTTC-3' and reverse, 5'-TCCGGAAGCAACACTC ATCC-3'; GAPDH forward, 5'-GATGCTGGTGCTGAG-3' and reverse, 5'-GTGGTGCAGGATGCATTGCTCTGA-3'; miR-29a-3p forward, 5'-ACCCCTTAGAGGATGACTGAT-3' and reverse, 5'-AACCGATTTCAGATGGTGCT-3'; and U6 forward, 5'-GCTTCGGCAGCACATA-3' and reverse, 5'-ATG GAACGCTTCACGA-3'.

Western blotting. Total protein was extracted from cell lysates. In order to detect the expression levels of $\beta$-catenin in the nuclear and cytoplasmic fractions, the proteins were extracted separately with Nuclear-Cytosol Extraction kits (Applygen Technologies, Inc.). Protein concentration was measured with a bicinchoninic acid kit and $40 \mu \mathrm{g}$ total protein was separated via sodium dodecyl sulfate-polyacrylamide gel electrophoresis $(10 \%, 120 \mathrm{~V}, 90 \mathrm{~min})$, and then separated proteins were transferred to polyvinylidene fluoride membranes $(90 \mathrm{~V}$, $90 \mathrm{~min}$ ). Membranes were then blocked with 5\% non-fat milk for $1 \mathrm{~h}$ at room temperature, and then incubated overnight at $4^{\circ} \mathrm{C}$ with primary antibodies (all purchased from Abcam) against IGF-1 (1:800; cat. no. ab182408), $\beta$-catenin (1:500; cat. no. ab16051), caspase-3 (1:5,000; cat. no. ab32351), Bax (1:500; cat. no. ab243140), GAPDH (1:5,000; cat. no. ab8245) and TATA-box-binding protein (TBP; 1:2,000; cat. no. ab171969). The next day, the membranes were incubated with horseradish peroxidase-labeled goat anti-rabbit secondary antibody (1:5,000; ab7090; Abcam) for $2 \mathrm{~h}$ at room temperature. The blots were detected with Pierce ${ }^{\mathrm{TM}}$ ECL Western Blotting Substrate (Pierce; Thermo Fisher Scientific, Inc.) and imaged with a ChemiDoc MP Imaging System (Bio-Rad Laboratories, Inc.). GAPDH was used as an internal reference for the total protein contents of the nuclear and cytoplasmic fractions, while TBP was used as an internal reference for nuclear proteins.

Cell counting kit- 8 (CCK-8) assay. Briefly, $5 \times 10^{4}$ cells/well $(100 \mu \mathrm{l})$ were cultured in 96 -well plates. After $48 \mathrm{~h}$, the medium was replaced with medium supplemented with $10 \mu \mathrm{l}$ CCK-8 reagent (Beyotime Institute of Biotechnology) and the cells were cultured for an additional $2 \mathrm{~h}$ at $37^{\circ} \mathrm{C}$. The optical density at $450 \mathrm{~nm}$ was measured using a microplate reader (model 680; Bio-Rad Laboratories, Inc.).

Colony formation assay. The cells in the logarithmic growth phase were digested with $0.25 \%$ trypsin and pipetted into single wells, and the cells were suspended in DMEM medium with $10 \%$ fetal bovine serum for later use. Then, 200 cells were seeded in a $10 \mathrm{ml}$ dish with pre-warmed culture medium at $37^{\circ} \mathrm{C}$, and gently rotated to evenly disperse the cells. The medium was changed twice a week. After 2 weeks, the medium was poured and the cells carefully washed twice with PBS. Paraformaldehyde at $4 \%$ was added to fix the cells for $15 \mathrm{~min}$ at room temperature. GIMSA staining solution was added and for $30 \mathrm{~min}$ at $2^{\circ} \mathrm{C}$. After washing, the sample was observed under a light microscope (magnification, $\mathrm{x} 40$ ) and the number of colonies with more than 50 cells was counted.

5-Ethynyl-2'-deoxyuridine (EdU) assay. The proliferative ability of cells was detected via an EdU assay. Briefly, $1 \times 10^{4}$ cells were seeded into the wells of a 96-well plate and cultured under an atmosphere of $5 \% \mathrm{CO}_{2} / 95 \%$ air at $37^{\circ} \mathrm{C}$. EdU (Guangzhou 

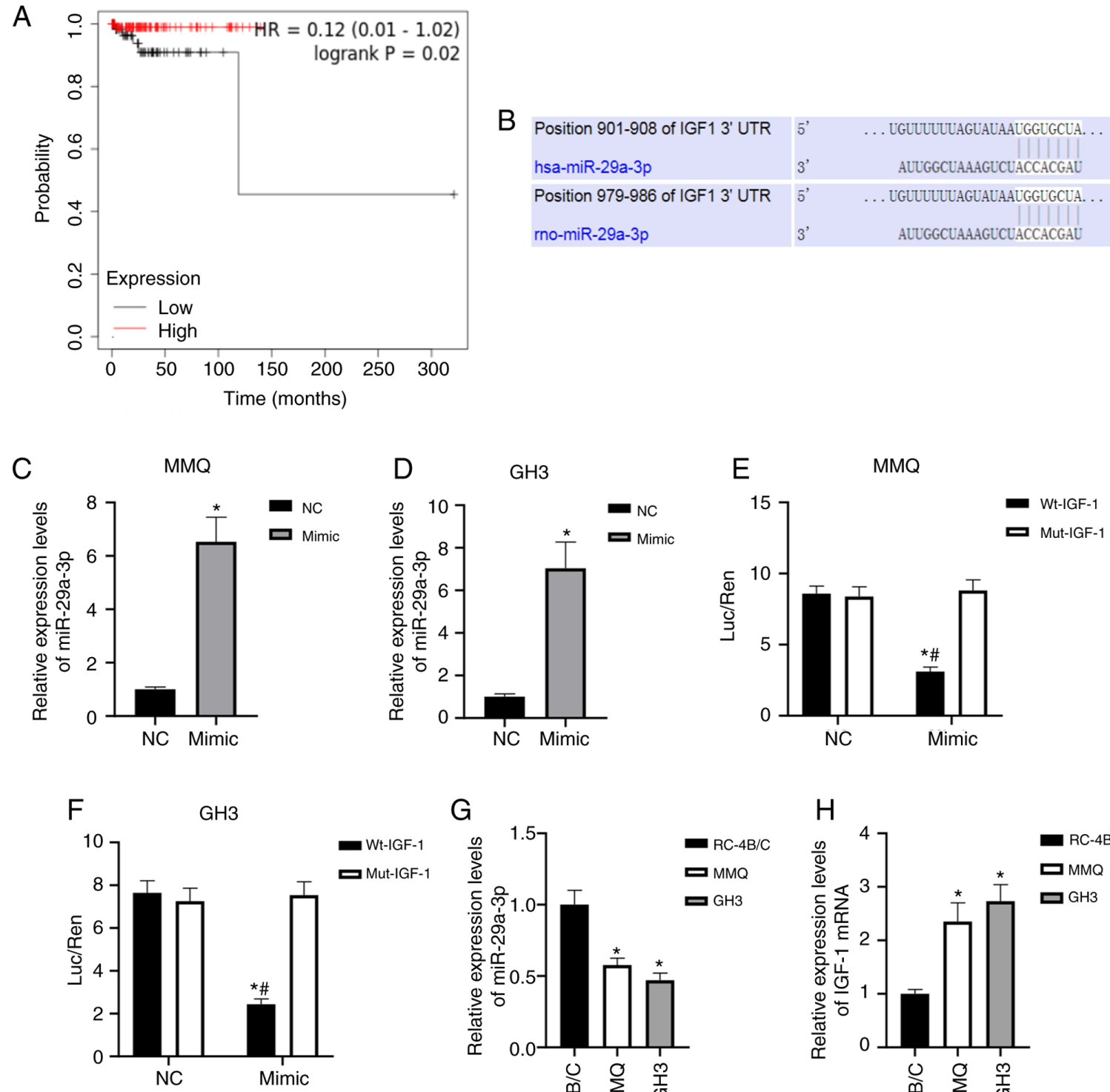

G

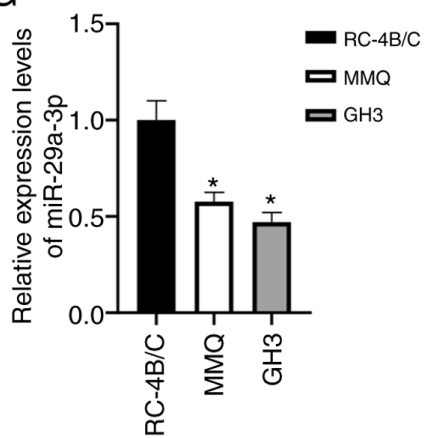

$\mathrm{H}$

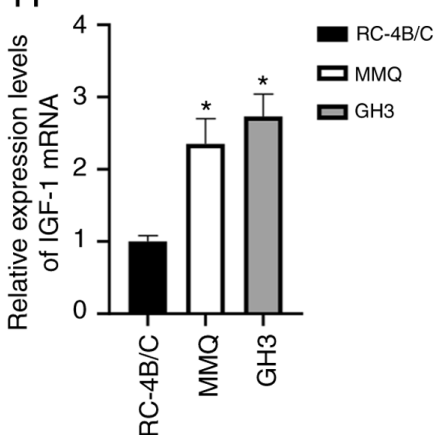

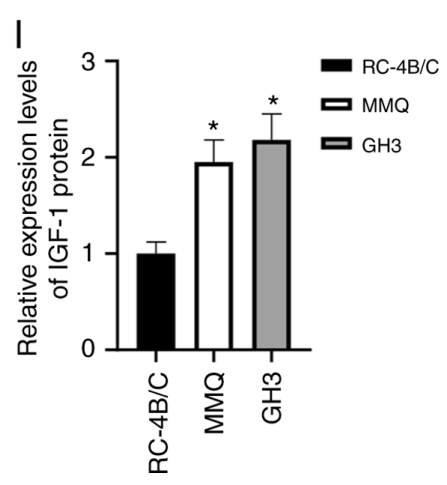

$J$

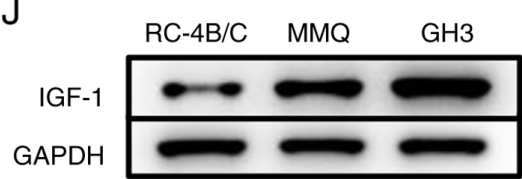

Figure 1. miR-29a-3p expression is low in prolactinoma cells and targets IGF-1. (A) The relationship between miR-29a-3p and the survival of patients with prolactinoma (pheochromocytoma and paraganglioma) was analyzed with the Kaplan-Meier method using data from The Cancer Genome Atlas. (B) The binding sites of the 3'-UTR of IGF-1 mRNA and miR-29a-3p. (C and D) The levels of miR-29a-3p in MMQ and GH3 cells after transfection with a miR-29a-3p mimic and NC. (E and F) The dual-luciferase reporter gene assay verified that miR-29a-3p bound to the 3'-UTR of IGF-1 mRNA. "P<0.05 vs. NC group; ${ }^{\#} \mathrm{P}<0.05$ vs. Mut-IGF-1 group. (G) The levels of miR-29a-3p in rat pituitary adenoma RC-4B/C cells and prolactinoma MMQ and GH3 cells. (H-J) IGF-1 mRNA and proteins levels in RC-4B/C, MMQ and GH3 cells. " $\mathrm{P}<0.05$ vs. NC or RC-4B/C or Wt-IGF-1. miR, microRNA; IGF-1, insulin-like growth factor; UTR, untranslated region; NC, negative control; Wt, wild-type; Mut, mutant.

RiboBio Co., Ltd.) was diluted to $10 \mu \mathrm{M}$ with culture medium and added to the wells. After incubation for $2 \mathrm{~h}$, the medium was discarded and the cells were washed, and then fixed with
$4 \%$ paraformaldehyde in phosphate-buffered saline and incubated for $30 \mathrm{~min}$ at room temperature. After washing, $100 \mu \mathrm{l}$ penetrant ( $0.5 \%$ Triton-X-100 in phosphate-buffered saline) was 
A
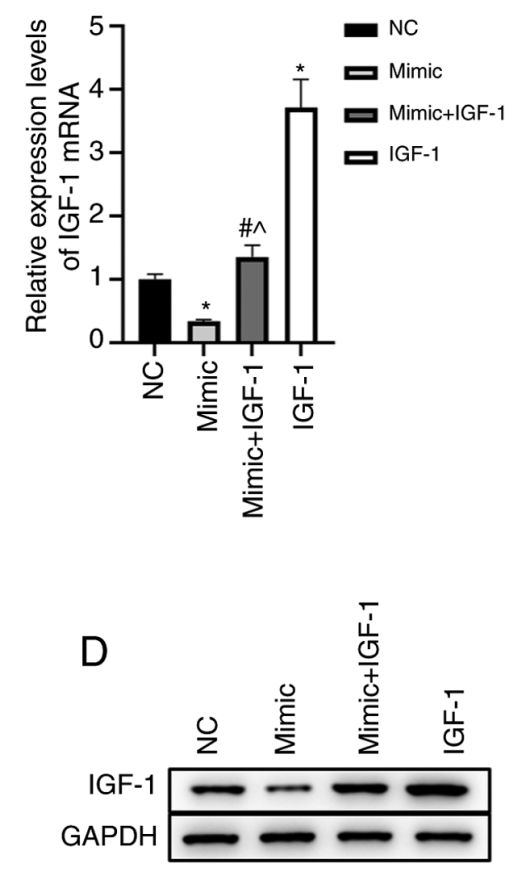

B

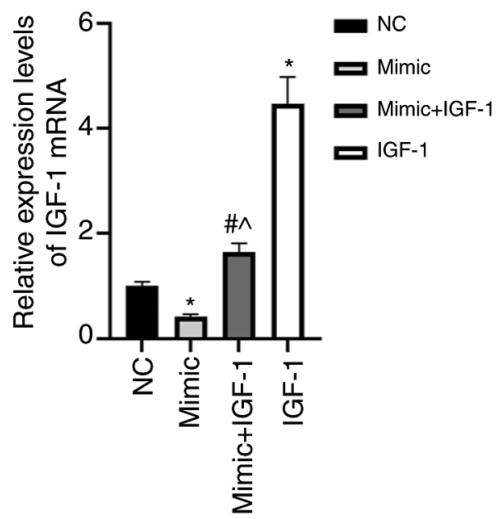

$\mathrm{E}$

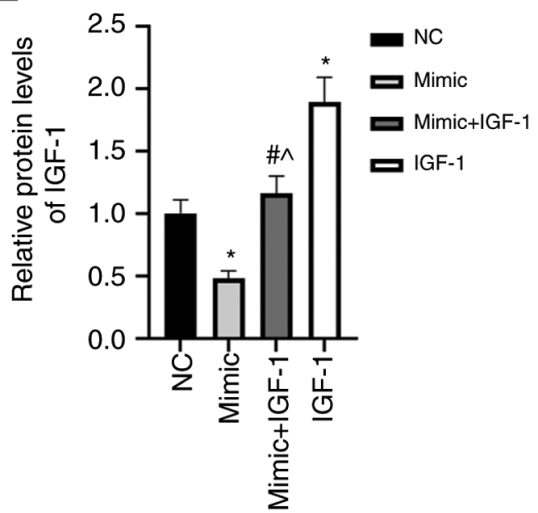

C

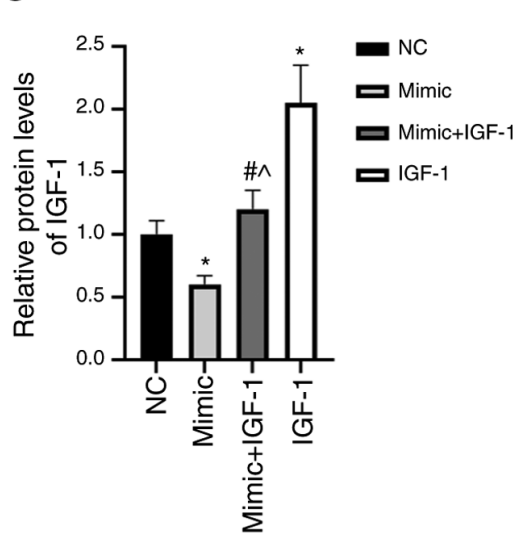

$\mathrm{F}$

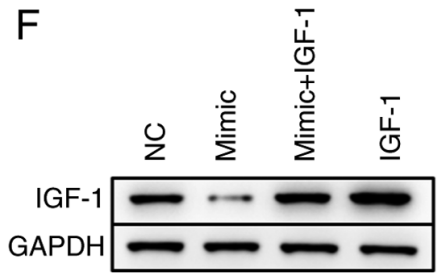

Figure 2. MicroRNA-29a-3p targets the inhibition of IGF-1 expression in prolactinoma cells. (A and B) IGF-1 mRNA levels in each group of cells. (C-F) IGF-1 protein levels in each group of cells. ${ }^{\mathrm{P}}<0.05$ vs. NC group; ${ }^{*} \mathrm{P}<0.05$ vs. mimic group; ${ }^{\wedge} \mathrm{P}<0.05$ vs. IGF-1 group. IGF-1, insulin-like growth factor; $\mathrm{NC}$, negative control.

added to each well and the plate was incubated in a decolorizing shaker for $10 \mathrm{~min}$. Afterward, the cells were washed, then $100 \mu$ 1 Apollo567 staining reaction solution (Guangzhou RiboBio Co., Ltd.) was added to the wells and the plate was incubated for $30 \mathrm{~min}$ at room temperature in the dark. After washing, the cells were fixed (4\% paraformaldehyde, room temperature, $1 \mathrm{~h}$ ) and observed under a fluorescence microscope (Olympus Corporation) at an excitation wavelength of $550 \mathrm{~nm}$ and emission wavelength of $565 \mathrm{~nm}$ (magnification, x200).

Flow cytometry assay. Briefly, the cells were treated with $5 \mu 1$ Annexin V-fluorescein isothiocyanate and propidium iodide (Tianjin Sungene Biotech Co., Ltd.) for 15 min in the dark, and then subjected to flow cytometry with a BD FACSCalibur flow cytometer (BD Biosciences) to measure apoptosis rates. FlowJo software version 7.6.2 (FlowJo LLC) was used for analysis.

Enzyme-linked immunosorbent assay (ELISA). After the cells were cultured for $48 \mathrm{~h}$, the culture medium was collected by centrifugation $(3,000 \mathrm{x} \mathrm{g} ; 10 \mathrm{~min}$; room temperature) and the levels of PRL (ab272780; Abcam) and GH (F15621; Shanghai Xitang Biotechnology Co., Ltd.) were detected with ELISA kits. In accordance with the manufacturer's instructions, antibodies and chromogenic reagents were added sequentially to the wells of the ELISA plates and incubated for the recommended periods of time. Finally, the optical density at $450 \mathrm{~nm}$ was measured and standard curves were generated to measure the concentrations of PRL and GH.
Statistical analysis. Experiments were repeated three times for each sample. All statistical analyses were conducted using GraphPad Prism 7.0 software (GraphPad Software, Inc.). The data are expressed as the mean \pm standard error of the mean. Variance among multiple groups was identified by one-way analysis of variance (ANOVA). Pairwise comparisons between groups were conducted using the Tukey's test following ANOVA. $\mathrm{P}<0.05$ was considered to indicate a statistically significant difference.

\section{Results}

$m i R-29 a-3 p$ expression is low in prolactinoma cells and targets $I G F-1$. In order to preliminarily analyze the significance of miR-29a-3p in prolactinoma, analysis of TCGA database showed that low expression of miR-29a-3p was associated with poor prognosis of patients with pheochromocytomas and paragangliomas $(\mathrm{P}=0.02$, Fig. $1 \mathrm{~A})$. The prediction results showed that there were binding sites between miR-29a-3p and the 3'-UTR of IGF-1 mRNA, and both are conserved (Fig. 1B). The target binding relationship was verified with the dual-luciferase reporter assay. After transfection with the miR-29a-3p mimic, miR-29a-3p expression significantly increased ( $\mathrm{P}<0.05$, Fig. 1C and D), transfection with miR-29a-3p mimic and Wt-IGF-1 decreased the relative luciferase activity in MMQ and GH3 cells, thereby confirming targeted binding (Fig. 1E and F). To initially explore the expression characteristics of miR-29a-3p and IGF-1 in prolactinoma, benign pituitary adenoma RC-4B/C cells were used as a control. The 
A

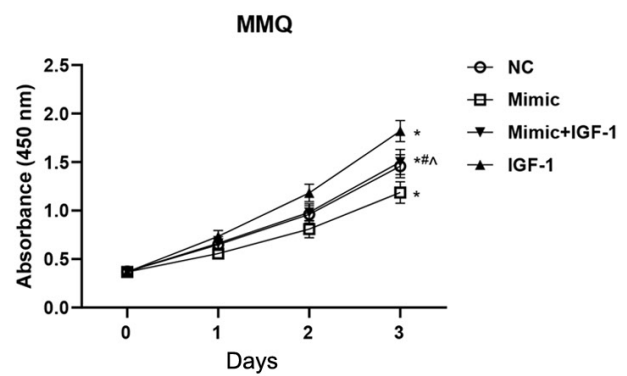

C

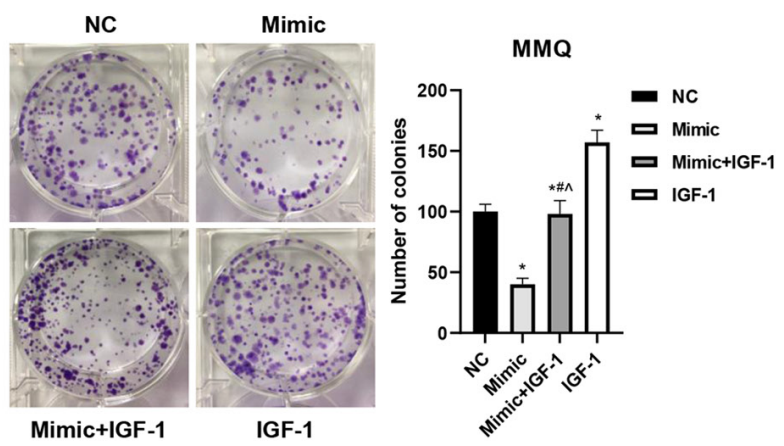

$\mathbf{E}$
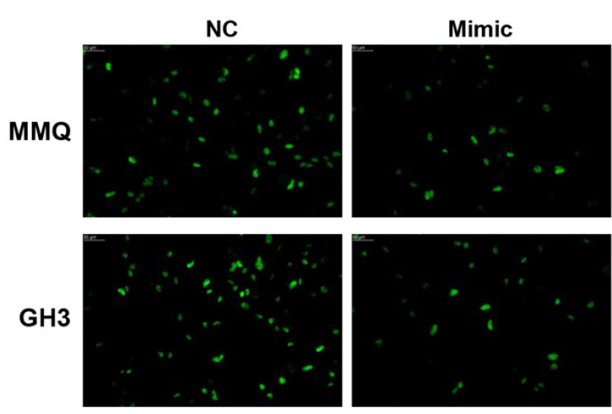

B

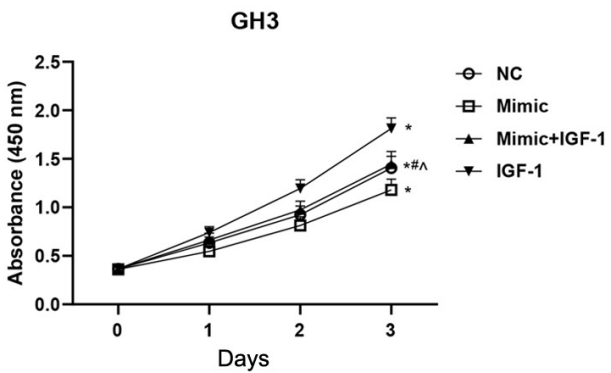

D

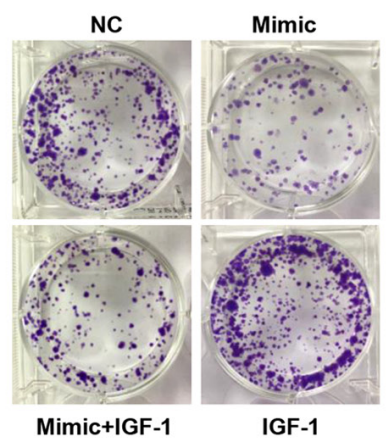

$\mathrm{GH} 3$

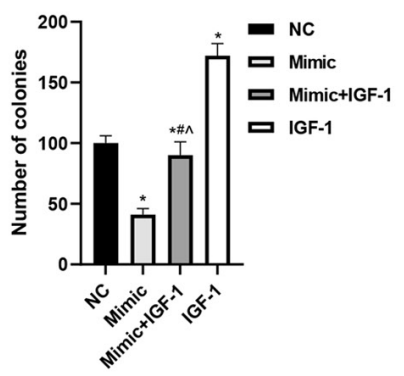

Figure 3. MicroRNA-29a-3p inhibits the proliferation of prolactinoma cells by inhibiting IGF-1. (A and B) Comparison of the viability of each group of cells. (C-E) Comparison of the proliferative ability of each group of cells. ${ }^{*} \mathrm{P}<0.05$ vs. NC group; ${ }^{*} \mathrm{P}<0.05$ vs. mimic group; ${ }^{\wedge} \mathrm{P}<0.05$ vs. IGF-1 group. IGF-1, insulin-like growth factor; NC, negative control.

results showed that miR-29a-3p expression was significantly downregulated and IGF-1 mRNA and protein levels were significantly upregulated in MMQ and GH3 prolactinoma cells $(\mathrm{P}<0.05$, Fig. 1G-J). The aforementioned data suggested that miR-29a-3p targeted IGF-1 and may play an important regulatory role in prolactinoma.

miR-29a-3p targets the inhibition of IGF-1 expression in prolactinoma cells. To further analyze the effects of miR-29a-3p/IGF-1 on prolactinoma, MMQ and GH3 cells were divided into four treatment groups: $\mathrm{NC}$, mimic, mimic + IGF-1, and IGF-1. The results showed that overexpression of miR-29a-3p significantly inhibited the mRNA and protein levels of IGF-1 $(\mathrm{P}<0.05)$, while transfection of IGF-1 pcDNA3.1 blocked the inhibitory effects of miR-29a-3p on IGF-1 (Fig. 2A-F). These findings suggested that miR-29a-3p strongly inhibited IGF-1 expression at the mRNA and protein levels in MMQ and GH3 cells.

miR-29a-3p inhibits the proliferation and promotes apoptosis of prolactinoma cells by inhibiting $I G F-1$. The viability, proliferation and apoptosis of cells in the four treatment groups were assessed with CCK-8, EdU and flow cytometry assays, respectively. The results showed that overexpression of miR-29a-3p inhibited the viability and proliferation of MMQ and GH3 cells. Overexpression of IGF-1 not only increased cell viability and promoted proliferation, but also significantly alleviated the inhibitory effects of miR-29a-3p $(\mathrm{P}<0.05$, Fig. 3A-E). Moreover, increased expression of miR-29a-3p significantly increased the apoptosis rates of MMQ and GH3 cells, while overexpression of IGF-1 had an opposite effect on apoptosis by neutralizing the effect of miR-29a-3p $(\mathrm{P}<0.05$, Fig. 4A-C). Correspondingly, the levels of apoptosis marker proteins caspase- 3 and Bax increased correspondingly after miR-29a-3p was overexpressed. The increased expression of IGF-1 significantly decreased the caspase- 3 and Bax protein levels of MMQ and GH3 cells, thus indicating that it reduced the apoptosis-promoting effect of miR-29a-3p $(\mathrm{P}<0.05$, Fig. 4D-F). These results suggested that miR-29a-3p inhibited proliferation and induced apoptosis of prolactinoma cells, which was closely related to the inhibition of IGF-1.

miR-29a-3p inhibits PRL and GH secretion of prolactinoma cells by targeting IGF-1. In order to further analyze the effect 
A

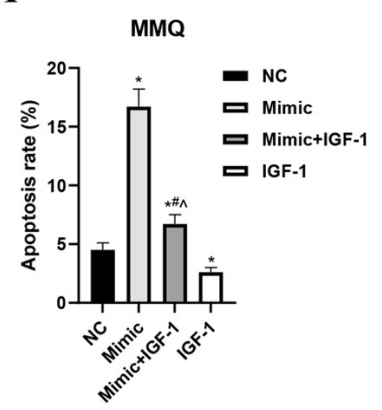

D

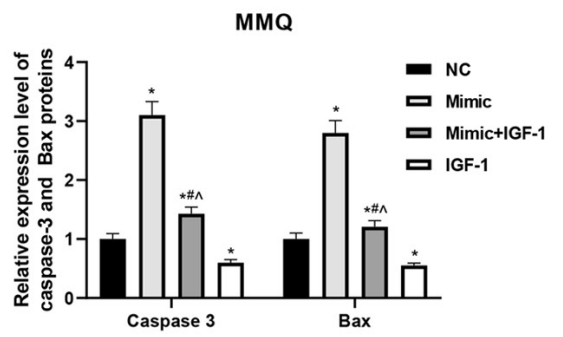

B C

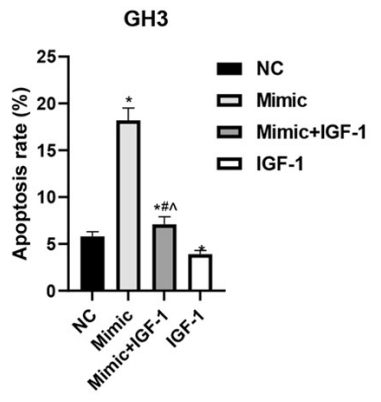

$\mathbf{E}$
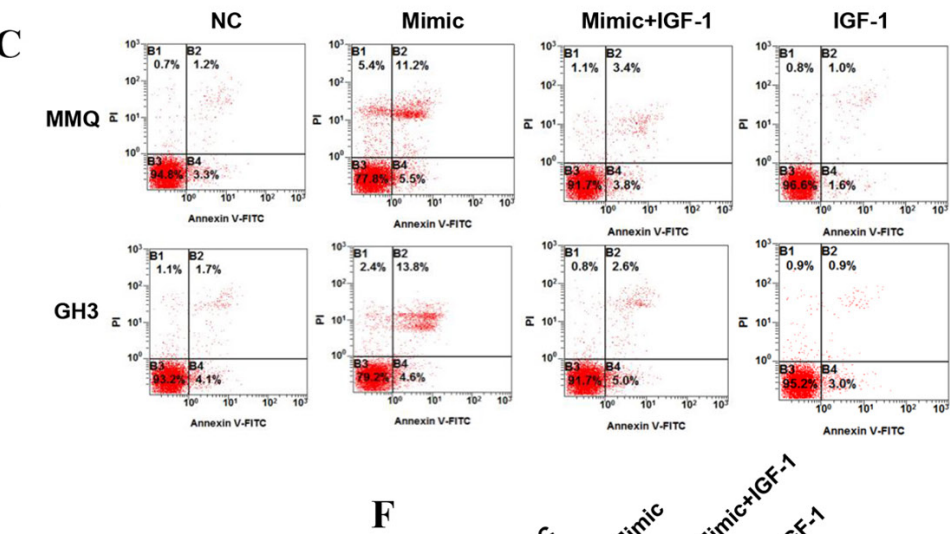

\section{(1)}

E
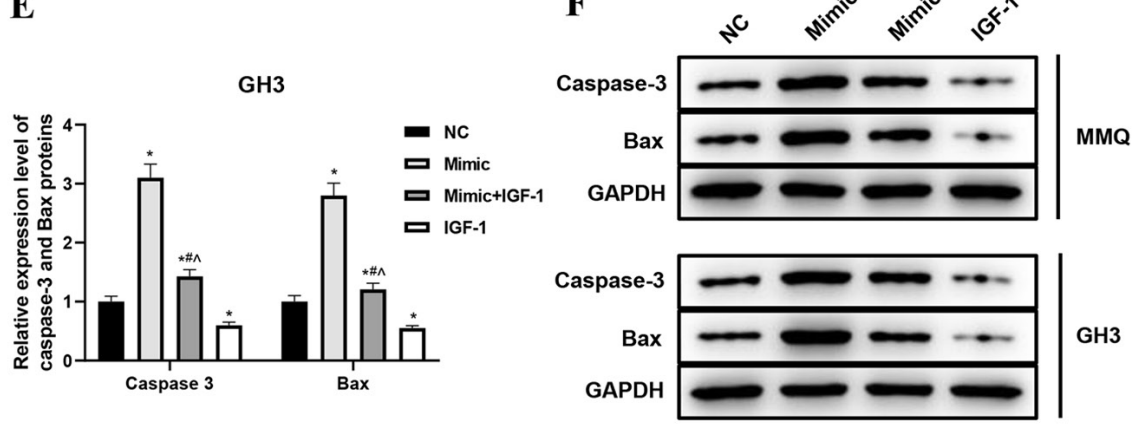

Figure 4. MicroRNA-29a-3p promotes apoptosis of prolactinoma cells by inhibiting IGF-1. (A-C) Comparison of the apoptosis rate of each group of cells. (D-F) Comparison of the expression levels of the apoptosis-related proteins caspase-3 and Bax among each group of cells. ${ }^{*} \mathrm{P}<0.05$ vs. NC group; ${ }^{*} \mathrm{P}<0.05$ vs. mimic group; ${ }^{\wedge} \mathrm{P}<0.05$ vs. IGF-1 group. IGF-1, insulin-like growth factor; NC, negative control.

of miR-29a-3p on prolactinoma cells, PRL mRNA levels in the cells and the PRL concentration in the culture medium were detected by RT-qPCR and ELISA, respectively. The results showed that the PRL mRNA expression and culture medium levels were significantly lower in the mimic group, and higher in the IGF-1 group than in the NC group, and significantly higher in the mimic + IGF-1 group compared with in the mimic group $(\mathrm{P}<0.05$, Fig. 5A-D). GH is mainly secreted by GH3 cells, with lower levels produced by MMQ cells (24). Overexpression of miR-29a-3p significantly lowered GH mRNA levels in GH3 cells and $\mathrm{GH}$ concentration in the medium as compared with the NC group. Overexpression of IGF-1 had the opposite effects and blocked the inhibitory effects of miR-29a-3p on the secretory function of GH3 cells $(\mathrm{P}<0.05$, Fig. $5 \mathrm{E}$ and $\mathrm{F})$. These results suggested that miR-29a-3p inhibited the expression and secretion of PRL and/or GH in MMQ and GH3 cells by inhibiting IGF-1.

Regulatory effects of miR-29a-3p/IGF-1 on prolactinoma is related to $\beta$-catenin. To further analyze the mechanism used by miR-29a-3p/IGF-1 to regulate the progression and secretion of prolactinoma, $\beta$-catenin levels were measured. The results showed that increasing miR-29a-3p expression significantly increased $\beta$-catenin levels in the cytoplasmic fractions and significantly decreased levels in the nuclear fractions of MMQ and GH3 cells. On the contrary, IGF-1 promoted $\beta$-catenin activation and translocation into the nucleus. In addition, overexpression of IGF-1 reversed the inhibitory effects of miR-29a-3p on $\beta$-catenin ( $\mathrm{P}<0.05$, Fig. 6A-D). Collectively, these results suggested that the effects of miR-29a-3p/IGF-1 on the proliferation, metastasis and secretion of MMQ and GH3 cells were related to $\beta$-catenin.

\section{Discussion}

Current treatment regimens for pituitary tumors involve the use hormones, which limits applications for the treatment of prolactinoma (25). Pituitary tumors secrete PRL and GH, which can cause additional physiological effects $(26,27)$. Therefore, it is of great significance to identify novel targets for the diagnosis and treatment of prolactinoma.

IGF-1, also known as somatomedin C, is produced by autocrine and paracrine cells, and is necessary for the physiological effects of GH. In a rat model of prolactinoma induced by $17-\beta$ estradiol, inhibition of IGF-1 alleviated serum levels of PRL and reduced the blood vessel density of prolactinoma (28). Imatinib is an IGF-1 inhibitor that also can inhibit the secretion of $\mathrm{GH}$ by GH3 cells in vitro (29). Clinical studies have reported that increased IGF-1 expression is associated with the proliferation of pituitary tumor cells and a poorer prognosis (30). The results of the present study suggested that inhibition of IGF-1 by exogenous methods could inhibit the growth of prolactinoma and reduce the secretion of PRL and GH. In vivo, IGF-1 is also targeted by miRNAs $(31,32)$. In polycystic ovary syndrome, IGF-1 is targeted by miR-323-3p and miR-323-3p/IGF-1 is involved in the regulation of steroid secretion and human cumulus cell function (33). miR-135a inhibits the proliferation and metastasis of lung cancer cells by targeting IGF-1 to inhibit the AKT pathway (34). In the present study, miR-29a-3p was downregulated and IGF-1 was upregulated in prolactinoma cells. Moreover, it was predicted and verified that miR-29a-3p was an upstream regulator of IGF-1 and, thus, presents a possible target to reduce IGF-1 mRNA and protein levels. These results also suggested that miR-29a-3p might play a role in the development and progression of prolactinoma by regulating IGF-1. 
A

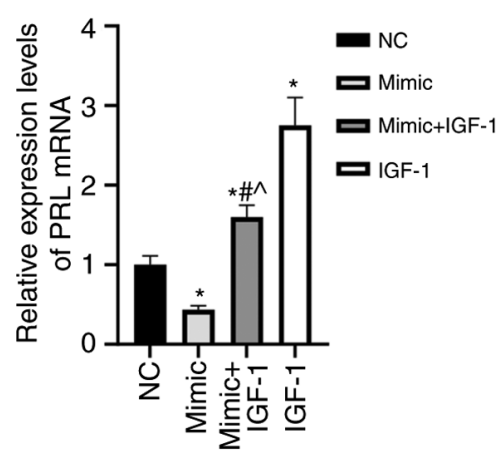

$\mathrm{D}$

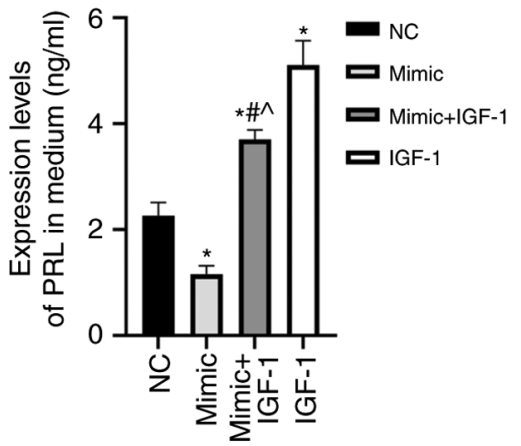

B

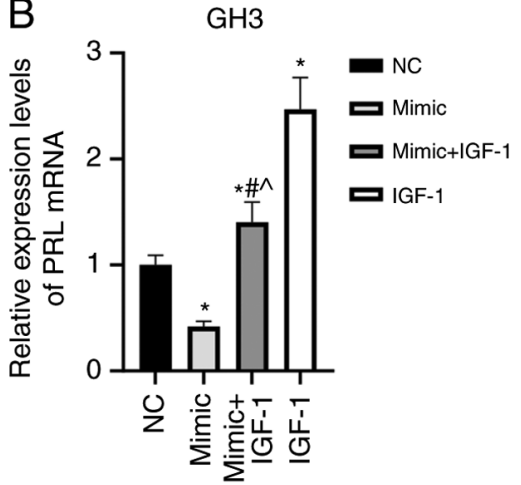

$\mathrm{E}$

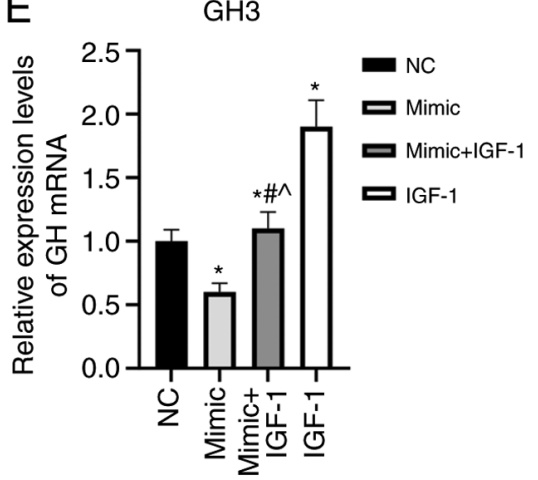

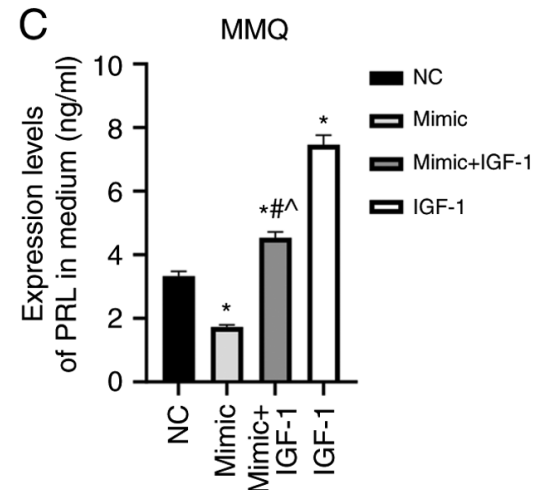

$\mathrm{F}$

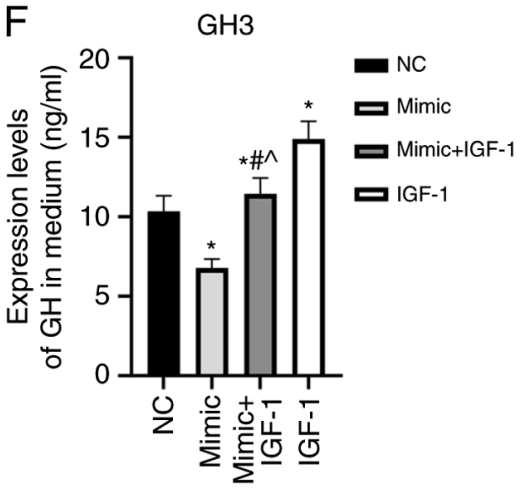

Figure 5. MicroRNA-29a-3p inhibits PRL and GH secretion of prolactinoma cells by targeting IGF-1. (A and B) Comparison of PRL mRNA levels in each group of cells. (C and D) Comparison of PRL levels in the medium of each group of cells. (E and F) Comparison of GH mRNA levels and GH concentrations in the culture medium of each group of GH3 cells. ${ }^{*} \mathrm{P}<0.05$ vs. NC group; ${ }^{\mathrm{P}} \mathrm{P}<0.05$ vs. mimic group; ${ }^{\wedge} \mathrm{P}<0.05$ vs. IGF-1 group. IGF-1, insulin-like growth factor; $\mathrm{NC}$, negative control; PRL, prolactin; GH, growth hormone.

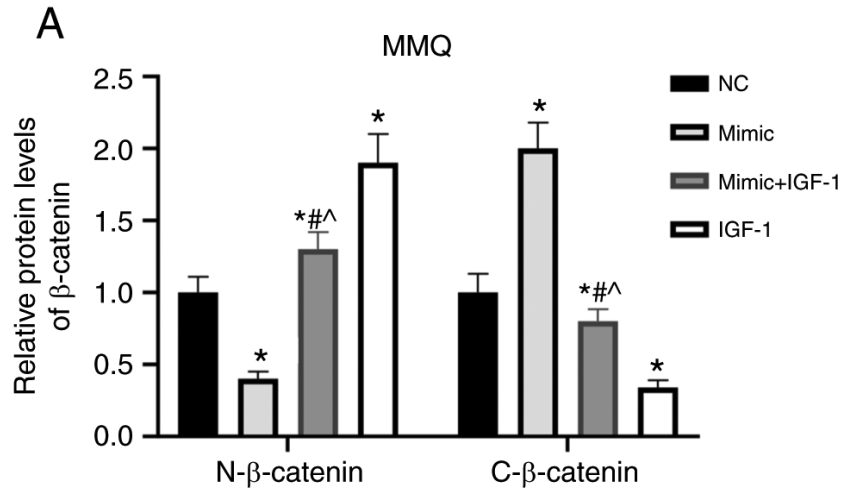

C

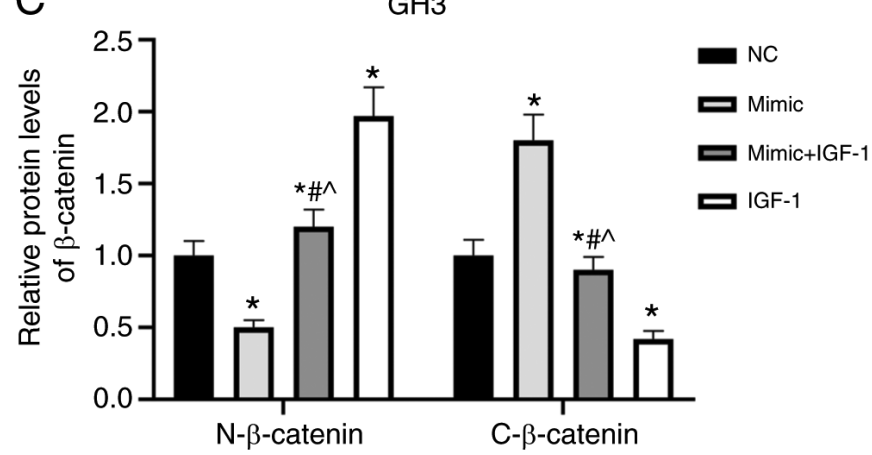

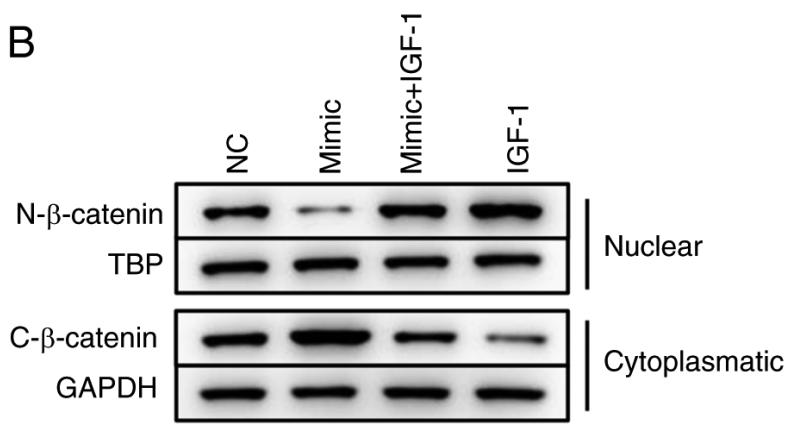

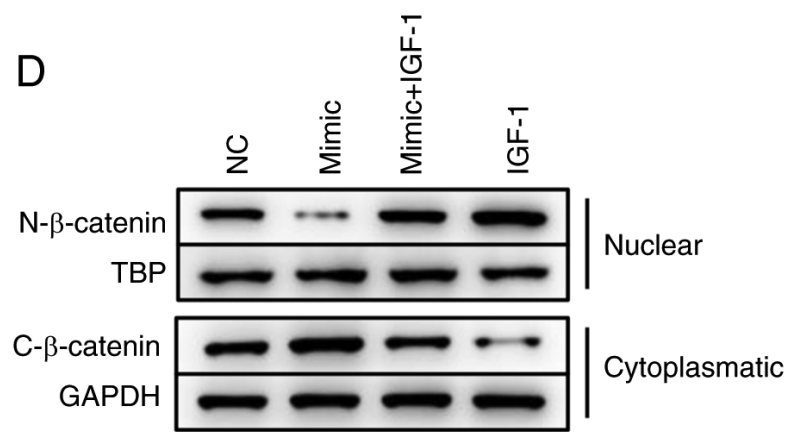

Figure 6. Regulatory effects of microRNA-29a-3p/IGF-1 on prolactinoma cells is related to $\beta$-catenin. (A-D) The protein expression levels of $\beta$-catenin in the cytoplasm and nucleus of each group of cells. GAPDH was used as a reference in the cytoplasmic fraction and TBP in the nuclear fraction. * $<0.05$ vs. NC group; ${ }^{\text {P }}<0.05$ vs. mimic group; ${ }^{\wedge} \mathrm{P}<0.05$ vs. IGF-1 group. IGF-1, insulin-like growth factor; NC, negative control; TBP, TATA-box-binding protein; $\mathrm{N}-$, nuclear; C-, cytoplasmic. 
In order to further analyze the effects of miR-29a-3p/IGF-1 on prolactinoma, miR-29a-3p and/or IGF-1 was overexpressed in MMQ and GH3 cells. The results showed that miR-29a-3p inhibited the proliferation and induced apoptosis of prolactinoma cells, while IGF-1 blocked the inhibitory effects of miR-29a-3p. miR-29a participates in inflammatory-induced damage and apoptosis of cardiomyocytes caused by obesity or oxidative stress via targeting the expression of IGF-1 $(35,36)$. Regarding the biological behavior of tumor cells, members of the miR-29 family inhibit the proliferation and induce apoptosis of breast cancer cells by inhibiting IGF-1 (37), as well as inhibiting the migration of vascular endothelial cells (38). Taken together, the results of the present and previous studies indicate that miR-29a-3p can inhibit the proliferation and induce apoptosis of prolactinoma cells, and these functions are related to the targeted inhibition of IGF-1 expression.

$\beta$-catenin, which is a key protein in the Wnt pathway, can enter the nucleus to regulate gene transcription. Inhibition of Wnt $/ \beta$-catenin can reduce PRL secretion by MMQ cells $(39,40)$. Inhibiting the nuclear translocation and inactivating the function of $\beta$-catenin can restore the proliferative ability of prolactinoma cells (41). The results of the present study showed that increasing the expression of miR-29a-3p inhibited the nuclear translocation of $\beta$-catenin in MMQ and GH3 cells, while inhibiting the secretion of PRL and/or GH. Overexpression of IGF-1 restored the retention of $\beta$-catenin in the cytoplasm caused by miR-29a-3p. A study by Lei et al (42) showed that miR-137 inhibited the proliferation and tumorigenesis of $\mathrm{GH} 3$ cells by inhibiting the expression of microphthalmia-associated transcription factor, and inhibiting the nuclear translocation of $\beta$-catenin can further strengthen the inhibitory effect of miR-137 on GH3 cells, suggesting that the inhibitory effect of miR-29a-3p on the biological behavior and secretory function of prolactinoma may be achieved by inhibiting $\beta$-catenin via a molecular mechanism that is inseparable from IGF-1. However, in addition to miR-29a-3p, there are other miRNAs that can target IGF-1. This has not yet been reported in prolactinoma, and thus we will focus on this area in future research. Moreover, the expression level and clinical significance of miR-29-3p in prolactinoma tissue samples still need to be further explored.

In conclusion, the level of miR-29a-3p in prolactinoma was suppressed, thus increasing miR-29a-3p expression may inhibit the proliferation of prolactinoma cells and the secretion of PRL and GH by targeting IGF-1 via mechanisms that may be related to the $\beta$-catenin pathway. However, further studies are needed to elucidate the relationship between miR-29a-3p and prolactinoma, and the underlying mechanism regulating IGF-1/ $\beta$-catenin in prolactinoma cells must be verified in vivo.

\section{Acknowledgements}

Not applicable.

\section{Funding}

No funding was received.

\section{Availability of data and materials}

The datasets used and/or analyzed during the current study are available from the corresponding author on reasonable request.

\section{Authors' contributions}

WY and JX contributed to the conception of the study. WY and JX confirm the authenticity of all the raw data. WY, SL, DM, WG, HL and JX performed the experiment. WY, SL, WG, DM, HL and JX contributed significantly to data analysis and manuscript preparation, including writing of the manuscript and constructive discussions. All authors read and approved the final manuscript.

\section{Ethics approval and consent to participate}

Not applicable.

\section{Patient consent for publication}

Not applicable.

\section{Competing interests}

The authors declare that they have no competing interests.

\section{References}

1. Glezer A and Bronstein MD: Prolactinomas. Endocrinol Metab Clin North Am 44: 71-78, 2015.

2. Vroonen L, Daly AF and Beckers A: Epidemiology and management challenges in prolactinomas. Neuroendocrinology 109: 20-27, 2019.

3. Blanco AM: Hypothalamic- and pituitary-derived growth and reproductive hormones and the control of energy balance in fish. Gen Comp Endocrinol 287: 113322, 2020.

4. Silveira MA, Zampieri TT, Furigo IC, Abdulkader F, Donato J Jr and Frazão R: Acute effects of somatomammotropin hormones on neuronal components of the hypothalamic-pituitary-gonadal axis. Brain Res 1714: 210-217, 2019.

5. Kubo T, Furujo M, Mori S, Imai K, Ueda Y, Tsukahara K, Morita H, Ogura K, Fukuhara S, Shimizu J, et al: An infant case of macroprolactinemia with transient idiopathic central precocious puberty. Endocr J 54: 825-828, 2007.

6. Tirosh A and Shimon I: Current approach to treatments for prolactinomas. Minerva Endocrinol 41: 316-323, 2016.

7. Faltermeier CM, Magill ST, Blevins LS Jr and Aghi MK: Molecular biology of pituitary adenomas. Neurosurg Clin N Am 30: 391-400, 2019.

8. Donoho DA and Laws ER Jr: The role of surgery in the management of prolactinomas. Neurosurg Clin N Am 30: 509-514, 2019.

9. Chen T, Zheng F, Tao J, Tan S, Zeng L, Peng X and Wu B: Insulin-like growth factor-1 contributes to mucosal repair by $\beta$-arrestin2-mediated extracellular signal-related kinase signaling in experimental colitis. Am J Pathol 185: 2441-2453, 2015.

10. Yoneyama Y, Lanzerstorfer P, Niwa H, Umehara T, Shibano T, Yokoyama S, Chida K, Weghuber J, Hakuno F and Takahashi SI: IRS-1 acts as an endocytic regulator of IGF-I receptor to facilitate sustained IGF signaling. Elife 7: e32893, 2018.

11. Lyons A, Coleman M, Riis S, Favre C, O'Flanagan $\mathrm{CH}$, Zhdanov AV, Papkovsky DB, Hursting SD and O'Connor R: Insulin-like growth factor 1 signaling is essential for mitochondrial biogenesis and mitophagy in cancer cells. J Biol Chem 292: 16983-16998, 2017.

12. Chen KC, Chen PH, Ho KH, Shih CM, Chou CM, Cheng CH and Lee CC: IGF-1-enhanced miR-513a-5p signaling desensitizes glioma cells to temozolomide by targeting the NEDD4L-inhibited Wnt/ß-catenin pathway. PLoS One 14: e0225913, 2019.

13. Cónsole GM, Hereñú CB, Camihort GA, Luna GC, Ferese $C$ and Goya RG: Effect of insulin-like growth factor-I gene therapy on the somatotropic axis in experimental prolactinomas. Cells Tissues Organs 190: 20-26, 2009.

14. Castillo AI and Aranda A: Differential regulation of pituitary-specific gene expression by insulin-like growth factor 1 in rat pituitary $\mathrm{GH} 4 \mathrm{C} 1$ and $\mathrm{GH} 3$ cells. Endocrinology 138: 5442-5451, 1997. 
15. Simonson B and Das S: MicroRNA therapeutics: The next magic bullet? Mini Rev Med Chem 15: 467-474, 2015.

16. Hu B, Mao Z, Du Q, Jiang X, Wang Z, Xiao Z, Zhu D, Wang X, Zhu Y and Wang H: miR-93-5p targets Smad7 to regulate the transforming growth factor- $\beta 1 / \mathrm{Smad} 3$ pathway and mediate fibrosis in drug-resistant prolactinoma. Brain Res Bull 149: 21-31, 2019.

17. Jian M, Du Q, Zhu D, Mao Z, Wang X, Feng Y, Xiao Z, Wang H and Zhu Y: Tumor suppressor miR-145-5p sensitizes prolactinoma to bromocriptine by downregulating TPT1. J Endocrinol Invest 42: 639-652, 2019

18. Xiao Z, Wang Z, Hu B, Mao Z, Zhu D, Feng Y and Zhu Y: MiR-1299 promotes the synthesis and secretion of prolactin by inhibiting FOXO1 expression in drug-resistant prolactinomas. Biochem Biophys Res Commun 520: 79-85, 2019.

19. Zhao X, Hou Y, Tuo Z and Wei F: Application values of miR-194 and miR-29 in the diagnosis and prognosis of gastric cancer. Exp Ther Med 15: 4179-4184, 2018.

20. Xu W, Li Z, Zhu X, Xu R and Xu Y: miR-29 family inhibits resistance to methotrexate and promotes cell apoptosis by targeting COL3A1 and MCL1 in osteosarcoma. Med Sci Monit 24: $8812-8821,2018$

21. Gao G, Liang X and Ma W: Sinomenine restrains breast cancer cells proliferation, migration and invasion via modulation of miR-29/PDCD-4 axis. Artif Cells Nanomed Biotechnol 47: 3839-3846, 2019.

22. Habibi P, Alihemmatti A, Alipour M, Nourazar A, Yousefi H Andalib S and Ahmadiasl N: Effects of exercise on miR-29 and IGF-1 expression and lipid profile in the heart of ovariectomized rat. Acta Endocrinol (Buchar) 12: 130-136, 2016.

23. Livak KJ and Schmittgen TD: Analysis of relative gene expression data using real-time quantitative PCR and the 2(-Delta Delta C(T)) method. Methods 25: 402-408, 2001.

24. Tang H, Zhu D, Zhang G, Luo X and Xie W: AFAP1-AS1 promotes proliferation of pituitary adenoma cells through miR-103a-3p to activate PI3K/AKT signaling pathway. World Neurosurg 130: e888-e898, 2019.

25. Molitch ME: Diagnosis and treatment of pituitary adenomas: A review. JAMA 317: 516-524, 2017.

26. Lamberts SW, de Quijada M and Klijn JG: The effect of tamoxifen on GH and PRL secretion by human pituitary tumors. J Endocrinol Invest 3: 343-347, 1980.

27. Watanabe D, Yagasaki H, Kojika S, Ogiwara M, Kinouchi H, Nakane T and Inukai T: GH/PRL-secreting pituitary macroadenoma associated with GNAS p.Gln227Leu mutation: Pediatric case report and review. Endocr J 66: 403-408, 2019.

28. Console GM, Herenu CB, Camihort GA, Luna GC Bracamonte MI, Morel GR and Goya RG: Insulin-like growth factor-I gene therapy reverses morphologic changes and reduces hyperprolactinemia in experimental rat prolactinomas. Mol Cancer 7: 13, 2008

29. Gupta P, Rai A, Mukherjee KK, Sachdeva N, Radotra BD, Punia RPS, Vashista RK, Hota D, Srinivasan A, Dhandapani S, et al: Imatinib inhibits $\mathrm{GH}$ secretion from somatotropinomas. Front Endocrinol (Lausanne) 9: 453, 2018.

30. Kempf J, Schmitz A, Meier A, Delfs N, Mueller B, Fandino J, Schuetz P and Berkmann S: Adenoma size and postoperative IGF-1 levels predict surgical outcomes in acromegaly patients: Results of the Swiss pituitary registry (SwissPit). Swiss Med Wkly 148: w14653, 2018
31. O'Neill BT, Lee KY, Klaus K, Softic S, Krumpoch MT, Fentz J, Stanford KI, Robinson MM, Cai W, Kleinridders A, et al: Insulin and IGF-1 receptors regulate FoxO-mediated signaling in muscle proteostasis. J Clin Invest 126: 3433-3446, 2016.

32. Cui X, Li M, He Z, Hu L, Liu J, Yan J and Hua L: MiR-302b-5p enhances the neuroprotective effect of IGF-1 in methyl-4-phenyl-1,2,3,6-tetrahydropyridine-induced Parkinson's disease by regulating inducible nitric-oxide synthase. Cell Biochem Funct 38: 1025-1035, 2020.

33. Wang T, Liu Y, Lv M, Xing Q, Zhang Z, He X, Xu Y, Wei Z and Cao Y: miR-323-3p regulates the steroidogenesis and cell apoptosis in polycystic ovary syndrome (PCOS) by targeting IGF-1. Gene 683: 87-100, 2019.

34. Zhou Y, Li S, Li J, Wang D and Li Q: Effect of microRNA-135a on cell proliferation, migration, invasion, apoptosis and tumor angiogenesis through the IGF-1/PI3K/Akt signaling pathway in non-small cell lung cancer. Cell Physiol Biochem 42: 1431-1446, 2017.

35. Liu Y, Hu Q, Ao J, Li H and Li M: Role of miR-92a-3p/PTEN axis in regulation of pancreatic cancer cell proliferation and metastasis. Zhong Nan Da Xue Xue Bao Yi Xue Ban 45: 280-289, 2020 (In English, Chinese).

36. Wang Y, Zhao R, Liu W, Wang Z, Rong J, Long X, Liu Z, Ge J and Shi B: Exosomal circHIPK3 released from hypoxia-pretreated cardiomyocytes regulates oxidative damage in cardiac microvascular endothelial cells via the miR-29a/IGF-1 pathway. Oxid Med Cell Longev 2019: 7954657, 2019.

37. Shastri AA, Saleh A, Savage JE, DeAngelis T, Camphausen K and Simone NL: Dietary alterations modulate the microRNA 29/30 and IGF-1/AKT signaling axis in breast cancer liver metastasis. Nutr Metab (Lond) 17: 23, 2020.

38. Li Z, Jiang R, Yue Q and Peng H: MicroRNA-29 regulates myocardial microvascular endothelial cells proliferation and migration in association with IGF1 in type 2 diabetes. Biochem Biophys Res Commun 487: 15-21, 2017.

39. Cao L, Gao H, Li P, Gui S and Zhang Y: The Wnt/ $\beta$-catenin signaling pathway is involved in the antitumor effect of fulvestrant on rat prolactinoma MMQ cells. Tumour Biol 35: 5121-5127, 2014.

40. Chauvet N, Romanò N, Meunier AC, Galibert E, Fontanaud P, Mathieu MN, Osterstock G, Osterstock P, Baccino E, Rigau V, et al: Combining cadherin expression with molecular markers discriminates invasiveness in growth hormone and prolactin pituitary adenomas. J Neuroendocrinol 28: 12352, 2016.

41. Wang C, Tan C, Wen Y, Zhang D, Li G, Chang L, Su J and Wang X: FOXP1-induced lncRNA CLRN1-AS1 acts as a tumor suppressor in pituitary prolactinoma by repressing the autophagy via inactivating Wnt/ $\beta$-catenin signaling pathway. Cell Death Dis 10: 499, 2019.

42. Lei C, Jing G, Jichao W, Xiaohui L, Fang Q, Hua G, Yazhou M and Zhang Y: MiR-137's tumor suppression on prolactinomas by targeting MITF and modulating Wnt signaling pathway. J Clin Endocrinol Metab 104: 6391-6402, 2019.

This work is licensed under a Creative Commons Attribution-NonCommercial-NoDerivatives 4.0 International (CC BY-NC-ND 4.0) License. 